\title{
Left atrial rupture in osteogenesis imperfecta
}

\author{
M E ROGERSON, * J D BUCHANAN, $\dagger$ C M MORGANS* \\ From the ${ }^{\star}$ Department of Cardiology, St Mary's Hospital, Portsmouth, and the †Department of Pathology, \\ Royal Naval Hospital, Gosport
}

SUMMARY A 60 year old man with features of osteogenesis imperfecta presented in biventricular failure with evidence of mitral regurgitation. He responded to conventional treatment but later collapsed and died at home. Necropsy showed a haemopericardium caused by a tear in the left atrium. There was also rupture of the mitral chordae tendineae.

Osteogenesis imperfecta is a heterogenous group of disorders of collagen biosynthesis ${ }^{1}$ characterised by osseous fragility and a familial incidence. Recent biochemical advances and genetic studies have allowed a detailed classification to be established. ${ }^{2}$

One subtype (Sillence type I) is characterised by blue sclerae, deafness, and fractures with or without dentinogenesis imperfecta. As with other connective tissue disorders (such as Marfan's syndrome and Ehlers-Danlos syndrome), cardiovascular anomalies have been described ${ }^{3}$ but they are rarely fatal.

\section{Case report}

A 60 year old white man was admitted after a second episode of paroxysmal nocturnal dyspnoea associated with a recent history of breathlessness. He could walk only ten yards, and had a productive cough but no orthopnoea.

He first presented with dyspnoea of sudden onset four years earlier when a pansystolic murmur was found. Atrial fibrillation subsequently developed. This responded to symptomatic treatment and he was discharged from follow up. He had smoked cigarettes, 10 per day, for many years and had a history of multiple fractures. There was no family history of cardiovascular disease; his father and one paternal cousin also had multiple fractures. His three children were well; a fourth died in infancy. There are no details of this child's illness.

Examination showed a small, kyphotic man who was anxious but in no distress. He was deaf, with

Requests for reprints to Dr M E Rogerson, D Level, East Wing, Southampton General Hospital, Southampton SO9 4XY. blue sclerae, normal tympanic membranes, and a short right leg. He was in fast atrial fibrillation with evidence of left ventricular enlargement, mitral regurgitation, and biventricular failure. An electrocardiogram showed atrial fibrillation and left ventricular hypertrophy. Chest $x$ ray confirmed cardiomegaly, kyphosis, and upper lobe blood diversion. Routine blood testing showed polycythaemia, increased concentrations of hepatic enzymes, and arterial hypoxaemia. $M$ mode echocardiography showed concentric left ventricular hypertrophy with early systolic prolapse of the posterior mitral valve leaflet and late systolic ballooning of the same leaflet (fig 1). The left atrium was normal. Spirometry showed a forced expiratory volume $(1 \mathrm{~s})$ of $1580 \mathrm{ml}$ and a forced vital capacity of $2090 \mathrm{ml}$ (ratio 76\%).

He was treated with digoxin, diuretics, and verapamil and he responded well. He discharged himself on the tenth day. The next day, his general practitioner assessed him as being in good health, but later that same day he collapsed and died. Necropsy showed a well nourished man with a barrel chest. The ribs were fragile and could be cut easily with simple scissors. Death was caused by a haemopericardium which was the result of left atrial rupture. The heart was considerably enlarged ( $625 \mathrm{~g}$ ) with predominent left ventricular hypertrophy but the myocardium was healthy. The mitral valve ring was enlarged $(16 \mathrm{~cm}$, normal, range $5 \cdot 3-10 \cdot 2 \mathrm{~cm}$ ), the valve cusps showed ballooning and prolapse that is typical of the floppy valve syndrome, and four elongated posterior chordae tendineae were ruptured. The left atrium was dilated and there were many endocardial striae (fig 2); some were haemorrhagic. The atrial wall adjacent to the left atrial appendage was ruptured at the site of a similar endocardial split. The position was appropriate for a jet 


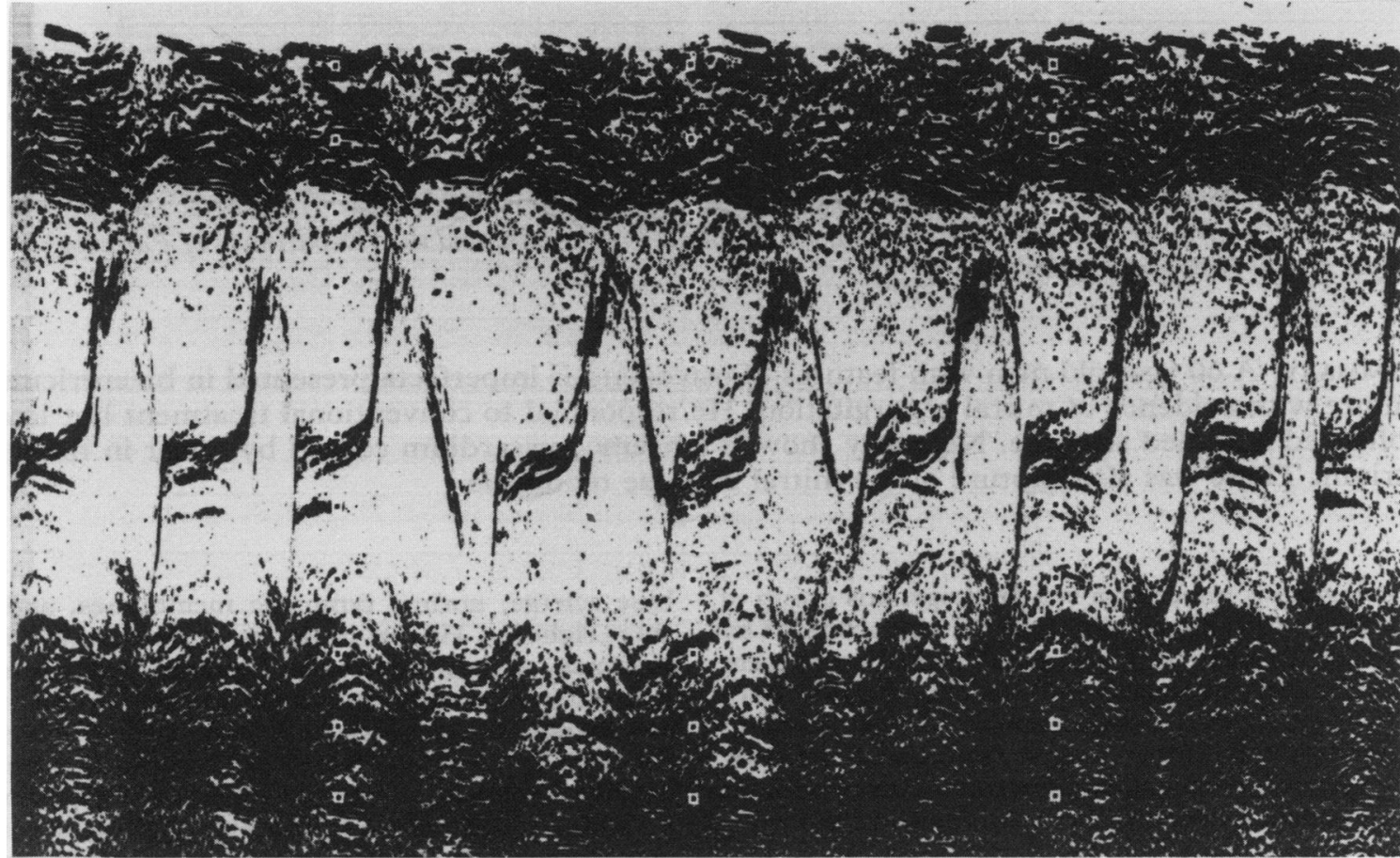

Fig $1 M$ mode echocardiograph showing early systolic prolapse of the posterior mitral valve leaflet.

lesion from the regurgitant mitral valve. There was a haemorrhage in the atrial wall that was continuous with the pericardial haematoma.

Apart from a congested "nutmeg" liver all other organs were normal. Histological examination confirmed myxoid and myxomatous degeneration of the mitral valve fibrosa. Intact chordae tendineae showed areas of wasting; those that were ruptured showed thin ruptured ends with excess elastic tissue on the frictional surfaces. The atrial wall showed linear splits in the subendocardial zone with interstitial haemorrhage or early organisation and scarring.

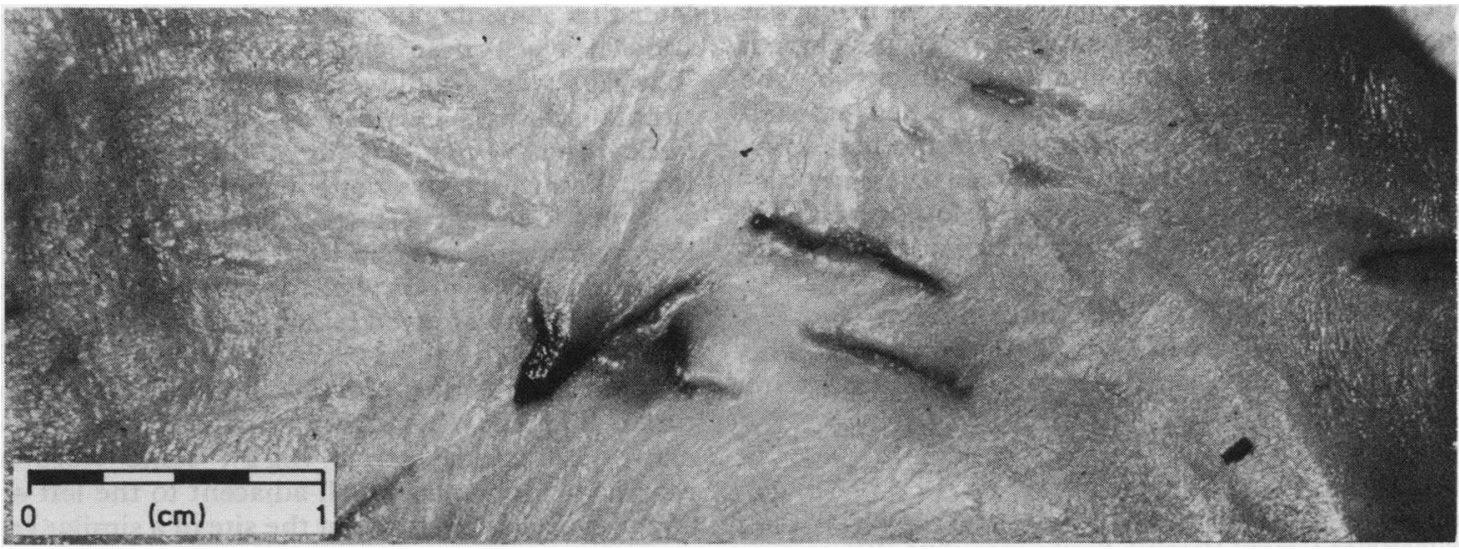

Fig 2 Inspection of the left atrium showed areas of linear splitting in the endocardium and adjacent striae. 


\section{Discussion}

Mitral regurgitation with myxoid degeneration of the valve cusps is recognised in Marfan and EhlersDanlos syndromes. ${ }^{3}$ The heart, however, is rarely affected by osteogenesis imperfecta. ${ }^{4}$ In some cases recognition of aortic valve disease has been followed by valve replacement. ${ }^{5}$ In a review of 23 reported cases of osteogenesis imperfecta, with serious cardiovascular disease, White et al found that $48 \%$ had abnormal mitral valves causing mitral regurgitation, whereas $87 \%$ had aortic regurgitation. The same group studied 20 symptom free patients and found cardiovascular abnormalities in all of them (seven were hypertensive and 13 has a soft late systolic murmur) ${ }^{6}$ Only one had echocardiographic mitral valve prolapse and none had important mitral regurgitation. Valve disease in osteogenesis imperfecta may be amenable to operation; however, the perioperative risks are increased both by a generalised bleeding tendency of uncertain cause and by decreased mobility. ${ }^{7}$

It is difficult to determine the frequency of valve disease in osteogenesis imperfecta because it is such a heterogeneous disorder. Four major types have been described, ${ }^{2}$ each with a distinct familial pattern. Each type may be expressed with variable penetrance, but in a given family the clinical features are similar. Only patients with the milder types of the disease (I and IV) generally survive to adulthood, hence reported cases must belong to these groups although specific features are not reported.

The floppy mitral valve is increasingly recognised in normal individuals ${ }^{8}$ and in patients with collagen disorders. Ninety cases were found in 1984 routine necropsies ${ }^{9}$; this resembled the frequency that was found by echocardiography..$^{10} \mathrm{Few}$ of the cases in which the chordae tendineae were intact had a valvar abnormality related to the cause of death; the floppy valve contributed to death in $39 \%$ of cases in which there was rupture of the chordae tendineae. The floppy valve is also found as an isolated abnormality in cases of sudden death; in most there are important ruptured chordae and mitral regurgitation. Haemopericardium is not reported.

Thus our patient appears to have had a mild form of osteogenesis imperfecta type I, with blue sclerae, deafness (predominantly conductive), and fragile bones. His death from left atrial rupture was an unusual complication of this generalised connective tissue disorder.

\section{References}

1 Smith R. Osteogenesis imperfecta. $\mathrm{Br} \mathrm{Med} \mathcal{f}$ 1984;289:394-6.

2 Sillence DO. Osteogenesis imperfecta: an expanding panorama of variants. Clin Orthop 1981;159:112-25.

3 McKusick VA. Heritable disorders of connective tissue. 4th ed. St Louis: CV Mosby, 1972:390-455.

4 Criscitiello MG, Ronan JA, Bestermann EMM, Schoenwetter W. Cardiovascular abnormalities in osteogenesis imperfecta. Circulation 1965;31:255-62.

5 Stein D, Kloster FG. Valvular heart disease in osteogenesis imperfecta. Am Heart f 1977;94:637-41.

6 White NJ, Winearls CG, Smith R. Cardiovascular abnormalities in osteogenesis imperfecta. Am Heart $\mathcal{F}$ 1983;106:1416-20.

7 Wood SJ, Thomas J, Braimbridge MV. Mitral valve disease and open heart surgery in osteogenesis imperfecta tarda. Br Heart f 1973;35:103-6.

8 Barlow JB, Pocock WA, Marchand P, Denny M. The significance of late-systolic murmurs. Am Heart $\mathcal{F}$ 1963;66:443-52.

9 Davies MJ, Moore BP, Braimbridge MV. The floppy mitral valve. Study of incidence, pathology, and complications in surgical, necropsy, and forensic material. Br Heart $\mathcal{F}$ 1978;40:468-81.

10 Procacci PM, Savran SV, Schreiter SL, Bryson AL. Prevalence of clinical mitral valve prolapse in 1169 young women. $N$ Engl $F$ Med 1976;294:1086-8. 